\title{
The Study of Fracturing Rock Body Damage and Cracks Propagation Model Basing on Catastrophe Theory
}

\author{
Zhao Wanchun*, Wang Tingting, Fu Xiaofei and Liu Yu \\ Northeast Petroleum University, Daqing, Heilongjiang, 163318, Research Institute of Petroleum Engineering, Dagang \\ Oilfield, Tianjin, 300280, China
}

\begin{abstract}
It is vital for the study of fracturing parameters optimal design and fluids rate forecast to calculate fracture propagation parameters accurately. In order to calculate fracture propagation accurately, in this paper, the model for calculating the value of energy release when the rock body collapses was established basing on catastrophe theory, considering that the collapse of fracturing rock body was caused by the accumulation of rock body deformation energy and releasing suddenly. And making the assumption that the energy that had released can be used for the propagation and extension of the cracks, the new model for calculating the parameters of cracks were established. The characteristics of sandstone rock mass were selected to study and analyze the fracturing parameters through laboratory experiment in daqing oilfield, the results show the maximum error between theoretical and the actual result is $9.71 \%$. The new method that was put forward this paper has important academic value to study fracturing propagation.
\end{abstract}

Keywords: Damage, energy release quantity, hydraulic fracturing, mutation model.

\section{INTRODUCTION}

The core issue of fracturing optimization design is the study of fractures propagation parameters, and the premise of reasonably selecting fracturing operation parameters and exactly assessing deliverability are accurately predicting fractures extension parameters. Domestic and foreign scholars have done a lot for the issue of describing fracturing parameters [1-11], but there are large deviation between the calculated results and the actual value. Previous studies on fracture morphology and extended tracks were based on fracture mechanics or damage mechanics criteria under the assumption that the whole process from the rock mass was loading until destruction was continued.

The rock mass deformation curve is shown in Fig. (1), from which it can be concluded that in the elastic deformation stage, the pore structure is constant (it can restore the initial state after unloading). In the damage deformation stage, the rock volume changes, and the internal pore structure is also changing. In order to describe the rock mass constitutive relation in damage stage, in this paper, the rock mass deformation behavior can be shown in Fig. (2). The rock body will deform and gather energy before the rock is destroyed under the process of fracturing. When the pump pressure reaches a certain value, the deformation of rock mass reaches a maximum, and the rock body will be destroyed suddenly. This kind of rock bursting suddenly and the release of energy make the rock body's steady state "jumping" to another steady state, and prompt the crack formation and propagation in rock body. The bursting process

*Address correspondence to this author at the School of Petroleum Engineering, Northeast Petroleum University, Daqing 163318, Heilongjiang, China; Tel: +860459-6504527; Fax: +860459-6503482;

E-mail: zhaowanchun520@163.com of the rock body can be described accurately by catastrophe theory. The catastrophe theory was regarded as a part of Chaos Theory, which was put forward by the French mathematician Renethom in 1972. Renethom considered the catastrophe as the integral "shock" of the system, and studied the phenomenon and rules that a thing transits from a steady state to another steady state whose process was continuous and the results were discontinuous. The catastrophe model mainly includes the cusp catastrophic model, folding catastrophe model, dovetail catastrophe, Butterfly Catastrophe etc. Each kind of catastrophe model is the mathematics abstract of different instability phenomenon in nature [12].

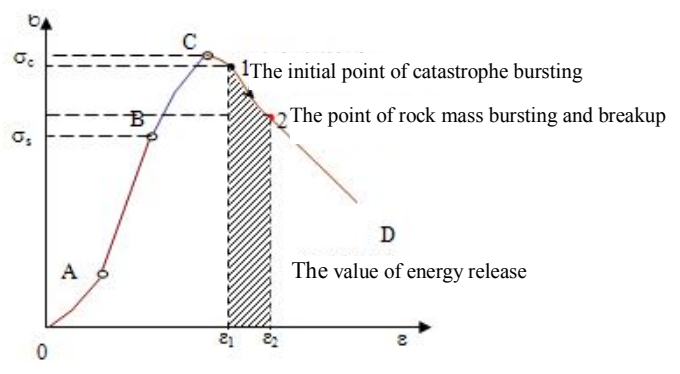

Fig. (1). The mass stress - strain curve in fracturing.

Liming Zhang, Yue Pan etc $[13,15]$ had proposed the essential difference between rock mass dynamic instability and elastic body geometry instability, and put forward the rationality of using principle of conservation of energy to solve the instability of rock mass, and the folding catastrophe model of rock burst in the circular cavern was established. And then Liming Zhang [16] thoroughly deliberated and discussed the related conclusions about the rock body 
catastrophe model of dynamic instability. As mentioned earlier, the cracks propagation process of hydraulic fracturing can be described clearly using folding catastrophe model. In this paper, the bursting process of the body from deformation to cracks initiation can be regard as the process of elastic deformation, damage degradation and the instability bursting. The damage variable in the process of rock body damage degradation was defined basing on rock porosity. The energy conservation equations of the transformation of work and energy before the rock cracks initiate were established, the body damage bursting folding catastrophe model in the fracturing and the value of energy release model when the body burst suddenly were established by the Taylor expansion of the energy conservation equation. Making the assumption that the released energy can be transformed into the energy consumed for the rock cracks initiation and propagation, the new model for calculating the propagation parameters of cracks was established. The daqing oil field actual block was selected to calculate the energy release vale of fracturing rock body, and the results of energy release vale and cracks propagation parameters were obtained. The research results of the paper can provide a new research method for subsequent cracks description and parameter calculation.

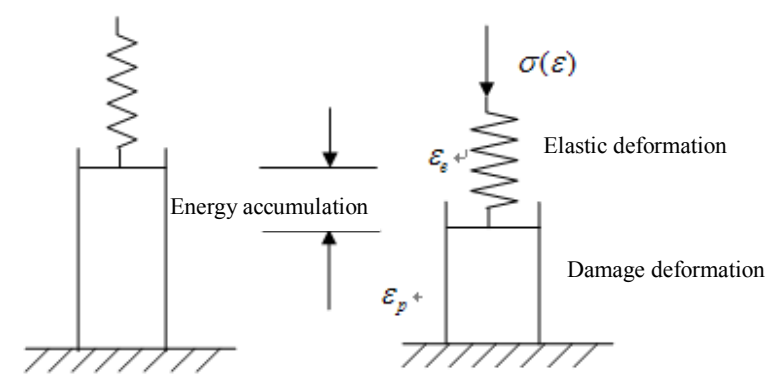

Fig. (2). The physical model of rock body deformation.

\section{THE DAMAGE DESCRIPTION OF FRACTURING ROCK BODY}

\subsection{The Definition of Damage Variable}

The internal pore structure will deform when the rock body becomes damage deformation. In order to characterize the constitutive relation of rock body damage, the damage variable of rock body deformation can be expressed as follows:

$$
\omega=\frac{\varphi_{0}-\varphi}{\varphi_{0}-\varphi_{\omega}}
$$

Where $\omega$ is the damage variable of rock body damage deterioration; $\varphi_{0}$ is the initial porosity of the rock body; $\varphi$ is the porosity in the process of rock body deformation in damage stage, which determines the damage degree of rock body; $\varphi_{\omega}$ is the porosity when the rock body bursts entirely, in general $\varphi_{\omega}=0.001$, and $\phi=\phi_{\omega}$.

\subsection{The Coupling Model of Rock Body Porosity}

The mass balance equation of rock body solid phase can be shown as follows:

$$
\frac{\partial}{\partial t}(1-\varphi) \rho_{s}-\nabla \cdot(1-\varphi) \rho_{s} v_{s}=0
$$

Where $v_{s}$ is the propagation velocity of sound waves in the solid phase; $\rho_{\mathrm{s}}$ is the density of the solid phase.

The volume strain can be shown as follows:

$\varepsilon_{V}=\nabla \cdot u_{s}$

$u_{s}$ is the deformation of the solid phase.

According to the definition of material derivative, formula (2) can be expressed as follows:

$$
\frac{d(1-\varphi)}{d t}+(1-\varphi) \frac{d \varepsilon_{V}}{d t}=0
$$

The relationship between porosity variation and volume strain can be shown as follows:

$$
\varphi=1-\left(1-\varphi_{0}\right) \exp \left(\varepsilon_{V}\right)
$$

Where $\varepsilon_{V}=\varepsilon_{x}+\varepsilon_{y}+\varepsilon_{z}$.

For different rock body, the relationship of axial strain and lateral strain can be obtained by rock compression experiment.

\section{THE ENERGY CONVERSION MODEL OF FRAC- TURING ROCK BODY}

The fracturing pump work force and potential energy of fracturing fluid can transform into elastic strain energy and damage strain energy, ignoring the rock body filtration kinetic energy of the fracturing fluid in fracturing. According to the principle of conservation of energy, the fracturing pump work and potential energy of fracturing fluid transform into the strain energy of the rock body, and the relationship can be expressed as follows:

$$
W_{b}+U_{h}-\left(E_{e}+E_{p}\right)=0
$$

Where $W_{b}$ is the work that the fracturing pumps have done on the rock body; $U_{h}$ is the potential energy of the fracturing fluid in the borehole; $E_{e}$ is the elastic strain energy of the rock body; $E_{p}$ is the damage strain energy of the rock body.

\subsection{The Work that the Fracturing Pumps have Done}

In the process of fracturing, the work that the pumps have done on the rock body can be expressed as follows:

$$
W_{b}=\eta \cdot P \cdot t
$$

Where $P$ is the horsepower of fracturing pumps; $t$ is the working time of the pumps; $\eta$ is the efficiency of the pumps, $\eta=0.6$.

\subsection{The Gravitational Potential Energy of Fracturing Fluid}

The gravitational potential energy of fracturing fluid in borehole can be expressed as follows:

$$
U_{h}=\frac{1}{2} \rho_{l} g \int_{0}^{h} d V_{l}
$$


Where $\rho_{l}$ is the density of fracturing fluid; $h$ is the vertical depth from wellhead to fracturing section; $d V_{l}$ is the infinitesimal volume of fracturing fluid.

\subsection{The Elastic Strain Energy of Rock Body}

The elastic strain energy of rock body per unit volume can be expressed as follows:

$$
E_{e}=\int_{0}^{\varepsilon_{e}} \sigma(\varepsilon) d \varepsilon
$$

Where $\varepsilon_{e}$ is the strain when the elastic deformation of rock body terminates; $\sigma(\varepsilon)$ is the stress loading on the internal face of fracturing perforation.

The constitutional relationship of rock body in elastic deformation stage can be shown as follows:

$$
\sigma(\varepsilon)=E \varepsilon
$$

Where $E$ is the Young's modulus of rock body.

\subsection{The Damage Strain Energy of Rock Body}

The strain energy of rock body damage deformation per unit volume can be expressed as follows:

$$
E_{p}=\int_{\varepsilon_{e}}^{\varepsilon_{b}} \sigma(\varepsilon) d \varepsilon
$$
cracks.

Where $\varepsilon_{b}$ is the damage strain before the rock body

According to the research results of literature [7] and literature [8] about damage degradation, combining formula (1), the rock body damage stress-strain constitutive equation can be expressed as follows:

$$
\sigma(\varepsilon)=\left(1-\sqrt{1-\ln \left[1+\frac{\omega\left(\varphi_{0}-\varphi_{\omega}\right)}{1-\varphi_{0}}\right]}\right) K \varepsilon^{\frac{1}{m}}
$$

Where $K, m$ is the material parameter of rock body.

\section{THE FOLDING CATASTROPHE MODEL OF FRACTURES CRACKING}

Substituting formula (7) and (8) into formula (6), expressing it using the differential form, and at the same time, being divided by $d \varepsilon$, the energy balance equation before rock body cracks can be obtained, which can be expressed as follows:

$$
\frac{\eta d(P t)}{d \varepsilon}+\frac{1}{2} \frac{g d\left(\rho_{l} \int_{0}^{h} d V_{l}\right)}{d \varepsilon}-\frac{\sigma(\varepsilon)}{E} \frac{d \sigma(\varepsilon)}{d \varepsilon}-\sigma(\varepsilon)=0
$$

It can be concluded that the work that the fracturing pumps have done and the potential energy of fracturing fluid make the fractures cracking. When $\frac{\eta d(P t)}{d \varepsilon}+\frac{1}{2} \frac{g d\left(\rho_{t} \int_{0}^{h} d V_{t}\right)}{d \varepsilon}>0$, the rock body is under the energy accumulation state before cracking, and the elastic strain energy accumulation gradually shifts to damage strain energy accumulation, and the rock body is in a state without cracking. When $\frac{\eta d(P t)}{d \varepsilon}+\frac{1}{2} \frac{g d\left(\rho_{t} \int_{0}^{h} d V_{i}\right)}{d \varepsilon}=0$, it can be seen that without fracturing pump work and the gravitational po- tential energy of fracturing fluid, only the accumulation of elastic strain energy making the increasing of damage strain energy, until the rock body cracks. According to the analysis from Fig. (1) and Fig. (2), it can be concluded that there is a turning point $\tilde{\varepsilon}$ on the damage curve segment, which can satisfy the relationship $\sigma^{\prime \prime}(\tilde{\varepsilon})=0$. According to formula (12), the turning point $\tilde{\varepsilon}$ is the point where the value of second-order derivative of formula (12) is 0 , which can be expressed as follows:

$$
\begin{aligned}
& \sigma^{\prime \prime}(\tilde{\varepsilon})=\frac{1-m}{m^{2}} \tilde{\varepsilon}^{\frac{1}{m}-2}\left(1-\sqrt{1-\ln \left[1+\frac{\omega\left(\varphi_{0}-\varphi_{\omega}\right)}{1-\varphi_{0}}\right]}\right) \\
& K+\frac{2}{m} \frac{d\left(1-\sqrt{\left.1-\ln \left[1+\frac{\omega\left(\varphi_{0}-\varphi_{\omega}\right)}{1-\varphi_{0}}\right]\right)}\right)_{\tilde{\varepsilon}^{\frac{1}{m}-1}}}{\left.+\frac{d^{2}\left(1-\sqrt{\left.1-\ln \left[1+\frac{\omega\left(\varphi_{0}-\varphi_{\omega}\right)}{1-\varphi_{0}}\right]\right)}\right.}{d \tilde{\varepsilon}^{2}}\right)_{\tilde{\varepsilon}^{\frac{1}{m}}}=0}
\end{aligned}
$$

Making $\sigma(\varepsilon)$ and $\sigma(\varepsilon) \cdot d \sigma(\varepsilon)$ in the energy balance equation for the rock body that does not crack Taylor expansion at $\tilde{\varepsilon}$, and $\sigma^{\prime \prime}(\tilde{\varepsilon})=0$, it can be obtained the relationship as follows:

$$
\begin{aligned}
& \sigma(\varepsilon)=\sigma(\tilde{\varepsilon})+\sigma^{\prime}(\tilde{\varepsilon}) \cdot(\varepsilon-\tilde{\varepsilon})+\frac{\sigma^{\prime \prime \prime}(\tilde{\varepsilon})}{6}(\varepsilon-\tilde{\varepsilon})^{3}+\mathrm{O}(\varepsilon-\tilde{\varepsilon})^{4} \\
& \sigma(\varepsilon) \frac{d \sigma(\varepsilon)}{d \varepsilon}=\sigma(\tilde{\varepsilon}) \cdot \sigma^{\prime}(\tilde{\varepsilon})+\left[\sigma^{\prime}(\tilde{\varepsilon})\right]^{2}(\varepsilon-\tilde{\varepsilon})+\frac{\left[\sigma(\tilde{\varepsilon}) \sigma^{\prime \prime \prime}(\tilde{\varepsilon})\right]}{2}(\varepsilon-\tilde{\varepsilon})^{2} \\
& +\frac{\left[\left(3 \sigma^{\prime}(\tilde{\varepsilon})+\sigma(\tilde{\varepsilon})\right) \sigma^{\prime \prime \prime}(\tilde{\varepsilon})+\sigma(\tilde{\varepsilon}) \sigma^{\prime \prime \prime}(\tilde{\varepsilon})\right]}{6}(\varepsilon-\tilde{\varepsilon})^{3}+\mathrm{O}(\varepsilon-\tilde{\varepsilon})^{4} \\
& \mathrm{O}(\varepsilon-\tilde{\varepsilon})^{4}=0
\end{aligned}
$$

The coefficient of $(\varepsilon-\tilde{\varepsilon})^{2}$ in formula (16) is $\frac{\left[\sigma(\tilde{\varepsilon}) \sigma^{\prime \prime \prime}(\tilde{\varepsilon})\right]}{2}$, which is not equal to 0 . According to the deterministic laws, substituting formula (15) and (16) into formula (13), and laying down the term whose order is higher than $(\varepsilon-\tilde{\varepsilon})^{2}$, it can be concluded:

$$
\begin{aligned}
& -\frac{1}{2}\left[(\varepsilon-\tilde{\varepsilon})+\frac{\left[\sigma^{\prime}(\tilde{\varepsilon})\right]^{2}}{\sigma(\tilde{\varepsilon}) \cdot \sigma^{\prime \prime \prime}(\tilde{\varepsilon})}\right]^{2}+ \\
& \frac{\left[\sigma^{\prime}(\tilde{\varepsilon})\right]^{4}+E\left(\frac{d W_{b}}{d \tilde{\varepsilon}}+\frac{d U_{h}}{d \tilde{\varepsilon}}\right) \sigma(\tilde{\varepsilon}) \cdot \sigma^{\prime \prime \prime}(\tilde{\varepsilon})-[\sigma(\tilde{\varepsilon})]^{3} \sigma^{\prime \prime \prime}(\tilde{\varepsilon})\left[\sigma^{\prime}(\tilde{\varepsilon})+E\right]}{[\sigma(\tilde{\varepsilon})]^{2}\left[\sigma^{\prime \prime \prime}(\tilde{\varepsilon})\right]^{2}}=0
\end{aligned}
$$

According to formula (12), the relationship at $\tilde{\mathcal{E}}$ can be shown as follows:

$$
\begin{aligned}
& \sigma(\tilde{\varepsilon})=\left[\left(1-\sqrt{1-\ln \left[1+\frac{\omega\left(\varphi_{0}-\varphi_{\omega}\right)}{1-\varphi_{0}}\right]}\right) K\right](\tilde{\varepsilon})^{\frac{1}{m}} \\
& \sigma^{\prime}(\tilde{\varepsilon})=\frac{1}{m}\left(1-\sqrt{1-\ln \left[1+\frac{\omega\left(\varphi_{0}-\varphi_{\omega}\right)}{1-\varphi_{0}}\right]}\right) K \tilde{\varepsilon}^{\frac{1}{m}-1} \\
& +\frac{d\left(1-\sqrt{1-\ln \left[1+\frac{\omega\left(\varphi_{0}-\varphi_{\omega}\right)}{1-\varphi_{0}}\right]}\right)}{d \tilde{\varepsilon}} K \tilde{\varepsilon}^{\frac{1}{m}}
\end{aligned}
$$




$$
\begin{aligned}
& \sigma^{\prime \prime \prime}(\tilde{\varepsilon})=\frac{(1-m)(1-2 m)}{m^{3}} \tilde{\varepsilon}^{\frac{1-3 m}{m}}\left(1-\sqrt{1-\ln \left[1+\frac{\omega\left(\varphi_{0}-\varphi_{\omega}\right)}{1-\varphi_{0}}\right]}\right) K \\
& +\frac{3(1-m)}{m^{2}} \tilde{\varepsilon}^{\frac{1-2 m}{m}} \frac{d\left(1-\sqrt{1-\ln \left[1+\frac{\omega\left(\varphi_{0}-\varphi_{\omega}\right)}{1-\varphi_{0}}\right]}\right)}{d \tilde{\varepsilon}} K \\
& +\frac{3}{m} \tilde{\varepsilon}^{\frac{1-m}{m}} \frac{d^{2}\left(1-\sqrt{1-\ln \left[1+\frac{\omega\left(\varphi_{0}-\varphi_{\omega}\right)}{1-\varphi_{0}}\right]}\right)}{d \tilde{\varepsilon}^{2}} K \\
& +\frac{d^{3}\left(1-\sqrt{1-\ln \left[1+\frac{\omega\left(\varphi_{0}-\varphi_{\omega}\right)}{1-\varphi_{0}}\right]}\right)}{d \tilde{\varepsilon}^{3}} \tilde{\varepsilon}^{\frac{1}{m}} K
\end{aligned}
$$

The folding catastrophe model of rock body damage cracking in fracturing can be shown by formula (18).

The folding catastrophe model can be written in the standard form, which can be shown as follows:

$$
x^{2}+\beta=0
$$

Where

$$
\begin{gathered}
x=(\varepsilon-\tilde{\varepsilon})+\frac{\left[\sigma^{\prime}(\tilde{\varepsilon})\right]^{2}}{\sigma(\tilde{\varepsilon}) \cdot \sigma^{\prime \prime \prime}(\tilde{\varepsilon})} \\
\beta=-2\left[\frac{\left[\sigma^{\prime}(\tilde{\varepsilon})\right]^{4}+E\left(\frac{d W_{b}}{d \tilde{\varepsilon}}+\frac{d U_{h}}{d \tilde{\varepsilon}}\right) \sigma(\tilde{\varepsilon}) \cdot \sigma^{\prime \prime \prime}(\tilde{\varepsilon})-[\sigma(\tilde{\varepsilon})]^{3} \sigma^{\prime \prime \prime}(\tilde{\varepsilon})\left[\sigma^{\prime}(\tilde{\varepsilon})+E\right]}{[\sigma(\tilde{\varepsilon})]^{2}\left[\sigma^{\prime \prime \prime}(\tilde{\varepsilon})\right]^{2}}\right]
\end{gathered}
$$

The two roots $x_{u}(<0)$ and $x_{0}=-x_{u}(>0)$ at any balance state in fracturing can satisfy the following relationship:

$$
\begin{aligned}
& x_{u}=(\varepsilon-\tilde{\varepsilon})+\frac{\left[\sigma^{\prime}(\tilde{\varepsilon})\right]^{2}}{\sigma(\tilde{\varepsilon}) \cdot \sigma^{\prime \prime \prime}(\tilde{\varepsilon})}= \\
& -\sqrt{-2\left[\frac{\left[\sigma^{\prime}(\tilde{\varepsilon})\right]^{4}}{[\sigma(\tilde{\varepsilon})]^{2}\left[\sigma^{\prime \prime \prime}(\tilde{\varepsilon})\right]^{2}}+\frac{E\left(\frac{d W_{b}}{d \tilde{\varepsilon}}+\frac{d U_{h}}{d \tilde{\varepsilon}}\right)}{\sigma(\tilde{\varepsilon}) \cdot \sigma^{\prime \prime \prime}(\tilde{\varepsilon})}-\frac{\sigma(\tilde{\varepsilon})\left[\sigma^{\prime}(\tilde{\varepsilon})+E\right]}{\sigma^{\prime \prime \prime}(\tilde{\varepsilon})}\right]} \\
& x_{a}=(\varepsilon-\tilde{\varepsilon})+\frac{\left[\sigma^{\prime}(\tilde{\varepsilon})\right]^{2}}{\sigma(\tilde{\varepsilon}) \cdot \sigma^{\prime \prime \prime}(\tilde{\varepsilon})}= \\
& \sqrt{-2\left[\frac{\left[\sigma^{\prime}(\tilde{\varepsilon})\right]^{4}}{[\sigma(\tilde{\varepsilon})]^{2}\left[\sigma^{\prime \prime \prime}(\tilde{\varepsilon})\right]^{2}}+\frac{E\left(\frac{d W_{b}}{d \tilde{\varepsilon}}+\frac{d U_{h}}{d \tilde{\varepsilon}}\right)}{\sigma(\tilde{\varepsilon}) \cdot \sigma^{\prime \prime \prime}(\tilde{\varepsilon})}-\frac{\sigma(\tilde{\varepsilon})\left[\sigma^{\prime}(\tilde{\varepsilon})+E\right]}{\sigma^{\prime \prime \prime}(\tilde{\varepsilon})}\right]}
\end{aligned}
$$

According to the standard form of formula (22), when $a>0$, the equation is meaningless. When $a \leq 0$, with the different value of $\mathrm{a}$, the value of $\mathrm{x}$ is different, which constitutes a parabolic curve. The arbitrary symmetric solutions of the corresponding two point on the parabolic curve express the two equilibrium state of the fracturing of rock body. When $\mathbf{x}<0$, in other words $(\varepsilon-\bar{\varepsilon})<\frac{-\left[\sigma^{\prime}(\tilde{\varepsilon})\right]^{2}}{\sigma(\tilde{\varepsilon}) \cdot \sigma^{\prime \prime}(\tilde{\varepsilon})}$, it is corresponding with the down branch of the parabolic curve. When $x>0$, in other words $(\varepsilon-\tilde{\varepsilon})>\frac{-\left[\sigma^{\prime}(\tilde{\varepsilon})\right]^{2}}{\sigma(\tilde{\varepsilon}) \sigma^{\prime \prime}(\tilde{\varepsilon})}$, it is corresponding with the up branch of the parabolic curve. The greater of the value of $|a|$, the greater of the difference value between two symmetric solutions on up and down branch, and it is not easily for the rock body to develop from one balance state to another balance state, that is, the farther distance from rock body bursting. With the increasing of the work that fracturing pumps have done and the potential energy of fracturing fluid, the value of $|a|$ is decreasing, and $\mathrm{x}$ develops from down branch to the origin (as shown in Fig. (3)).

It can be concluded from the analysis of the mechanics behavior of fracturing rock body bursting that when the body catastrophe burst, it can satisfy that $\frac{d W_{b}}{d \tilde{\varepsilon}}+\frac{d U_{h}}{d \tilde{\varepsilon}}=0$. The value of branch point $\left(x_{1}(<0)\right.$ and $\left.x_{2}=-x_{1}(>0)\right)$ can be expressed as follows:

$$
\begin{aligned}
& x_{u\left(\frac{d W_{b}}{d \tilde{\varepsilon}}+\frac{d U_{h}}{d \tilde{\varepsilon}}=0\right)}=(\varepsilon-\tilde{\varepsilon})+\frac{\left[\sigma^{\prime}(\tilde{\varepsilon})\right]^{2}}{\sigma(\tilde{\varepsilon}) \cdot \sigma^{\prime \prime \prime}(\tilde{\varepsilon})}= \\
& -\sqrt{-2\left[\frac{\left[\sigma^{\prime}(\tilde{\varepsilon})\right]^{4}}{[\sigma(\tilde{\varepsilon})]^{2}\left[\sigma^{\prime \prime \prime}(\tilde{\varepsilon})\right]^{2}}-\frac{\sigma(\tilde{\varepsilon})\left[\sigma^{\prime}(\tilde{\varepsilon})+E\right]}{\sigma^{\prime \prime \prime}(\tilde{\varepsilon})}\right]} \\
& x_{a\left(\frac{d W_{b}}{d \tilde{\varepsilon}}+\frac{d U_{h}}{d \tilde{\varepsilon}}=0\right)}=(\varepsilon-\tilde{\varepsilon})+\frac{\left[\sigma^{\prime}(\tilde{\varepsilon})\right]^{2}}{\sigma(\tilde{\varepsilon}) \cdot \sigma^{\prime \prime \prime}(\tilde{\varepsilon})}= \\
& \sqrt{-2\left[\frac{\left[\sigma^{\prime}(\tilde{\varepsilon})\right]^{4}}{[\sigma(\tilde{\varepsilon})]^{2}\left[\sigma^{\prime \prime \prime}(\tilde{\varepsilon})\right]^{2}}-\frac{\sigma(\tilde{\varepsilon})\left[\sigma^{\prime}(\tilde{\varepsilon})+E\right]}{\sigma^{\prime \prime \prime}(\tilde{\varepsilon})}\right]}
\end{aligned}
$$

Integrating formula (22), the total potential energy function of folding catastrophe model for fracturing rock body can be shown as follows:

$$
\Pi=\frac{1}{3} x^{3}+\beta x
$$

The critical equilibrium state point $\left(x_{u}\right)$ before the rock body cracks satisfies the following relationship:

$$
\Pi_{u}=\frac{1}{3} x_{u}^{3}+\beta x_{u}
$$

The equilibrium state point $\left(x_{a}\right)$ after the rock body cracks satisfies the following relationship:

$$
\Pi_{a}=\frac{1}{3} x_{a}^{3}+\beta x_{a}
$$

According to the laws of Dirichlet, when $x<0$ and $\frac{\partial^{2} \Pi}{\partial x^{2}}<0$, the system is under unstable state. When $x>0$ and $\frac{\partial^{2} \Pi}{\partial x^{2}}>0$, the system reaches a new steady state. If $\mathrm{x}$ transits from down branch to up branch through origin point, the damage of the rock body is asymptotic expression. If $x$ transits suddenly from down branch to up branch through a certain point, the damage of the rock body is catastrophe bursting, and the value of energy release can be shown in Fig. (3). 


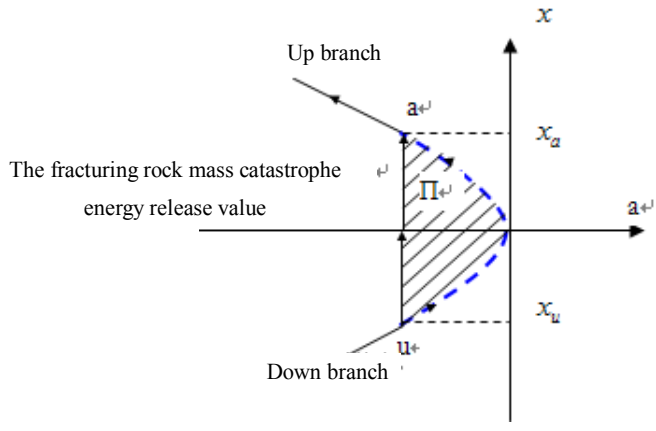

Fig. (3). The rock body catastrophe bursting in hydraulic fracturing.

When the body transits from $x_{u}$ to $x_{a}$, the rock body become instability bursting, forming cracks, and the energy release value can be shown as follows:

$$
\Delta \Pi=\frac{1}{3}\left(x_{a}^{3}-x_{u}^{3}\right)+\beta\left(x_{a}-x_{u}\right)
$$

Where $x_{a}=-x_{u}, x_{a}^{2}=x_{u}^{2}=-\beta$. By regularizing, the energy release value when the rock body transits can be shown as follows:

$$
\Delta \Pi=-\frac{4}{3} x_{a}^{3}=-\frac{4}{3}\left[2\left[\frac{\sigma(\tilde{\varepsilon})\left[\sigma^{\prime}(\tilde{\varepsilon})+E\right]}{\sigma^{\prime \prime \prime}(\tilde{\varepsilon})}-\frac{\left[\sigma^{\prime}(\tilde{\varepsilon})\right]^{4}}{[\sigma(\tilde{\varepsilon})]^{2}\left[\sigma^{\prime \prime \prime}(\tilde{\varepsilon})\right]^{2}}\right]\right]^{\frac{3}{2}}
$$

Formula (33) is the model for calculating energy release value when the rock body burst suddenly and form hydraulic fractures in the process of fracturing.

\section{THE CALCULATION OF CRACKS PROPAGA- TION PARAMETER}

Assuming that the crack is open type fracture, which can be shown in Fig. (4).

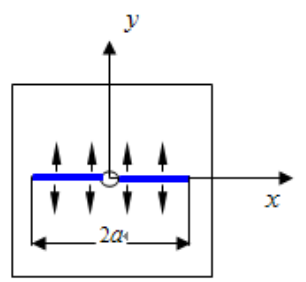

Fig. (4). The schematic diagram of crack propagation.

According to the geometric relations in the figure, the relationship between the energy release of rock body and crack propagation length can be shown as follows:

$$
\Delta \Pi=2 \int_{0}^{a} G d A=2 \frac{\left(1-v^{2}\right)}{E} \int_{0}^{a} K_{\mathrm{I}}^{2} d a
$$

Where

$$
K_{\mathrm{I}}=\sigma(\tilde{\varepsilon}) \sqrt{\pi a}
$$

Where $K_{I}$ is stress intensity factor; $a$ is crack propagation length.

\section{CASE STUDY}

A certain research block in Daqing oil field was selected for experiment. The experimental cores were obtained by sealed coring from $1408.44 \sim 1440.98 \mathrm{~m}$, $1707.74 \sim 1739.59 \mathrm{~m}$ and $849.17-976.63 \mathrm{~m}$ three intervals. The cores were divided into three groups. According to rock mechanical test requirement, the rock mechanical parameters were measured respectively, and the measurement results can be shown in Table 1. According to the measured results, we made the cores by ourselves, and conducted fracturing test. The energy release value when the rock body bursting suddenly and fractures propagation parameters were calculated, the results can be shown in Table 2 . The measured related results were shown in the below figure.

According to the rock body at different depth in a certain block of Daqing oil field, using the folding catastrophe model proposed in this paper, the cracks propagation energy release value of damaged rock body was calculated, and on this basis, the rock body cracks propagation length was calculated, and the accuracy of the model is verified by laboratory test, which was shown in Table 2 . By comparison, the maximum error between theoretical and the actual result is $9.71 \%$. The new calculation method is in good agreement with the actual.

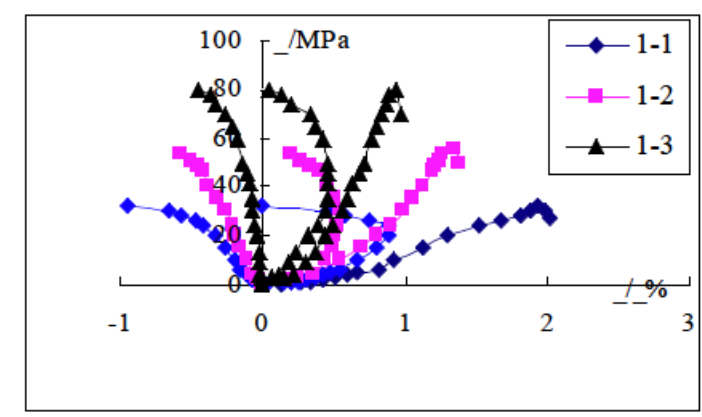

Fig. (5). The axial strain, radial strain and volume strain curves of group 1 cores.

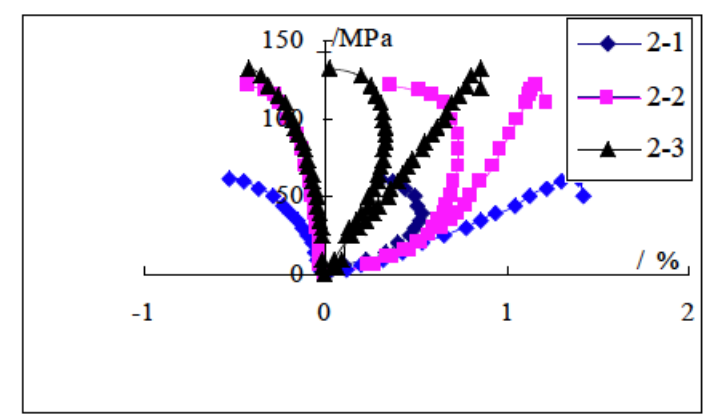

Fig. (6). The axial strain, radial strain and volume strain curves of group 2 cores.

\section{CONCLUSION}

(1) The cracks propagation calculation model in fracturing was established basing on catastrophe theory. The energy release value and cracks propagation parameters calculation model when the rock body bursting suddenly and form cracks were established basing on principle of conservation of energy. 


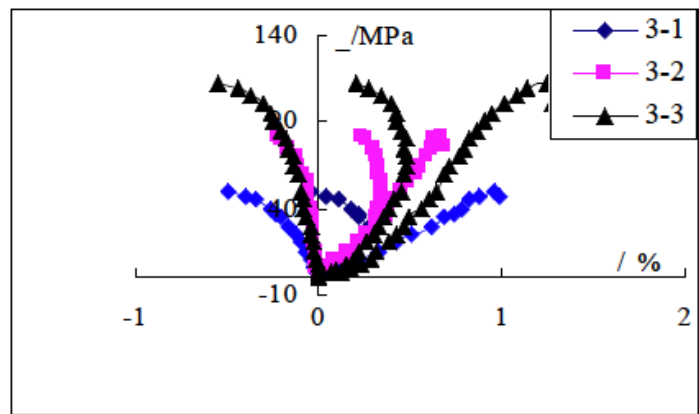

Fig. (7). The axial strain, radial strain and volume strain curves of group 3 cores.

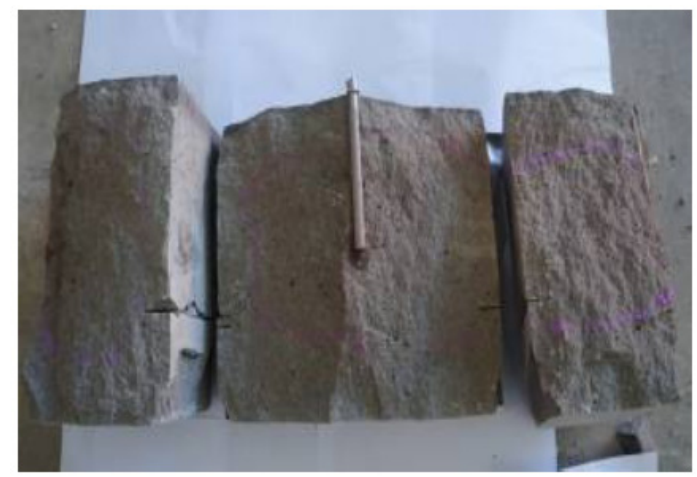

Fig. (9). The fracturing results of laboratory test of group 2 cores.

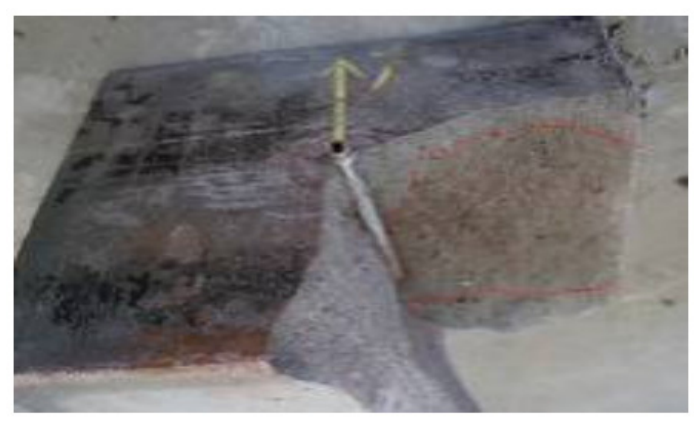

Fig. (8). The fracturing results of laboratory test of group 1 cores.

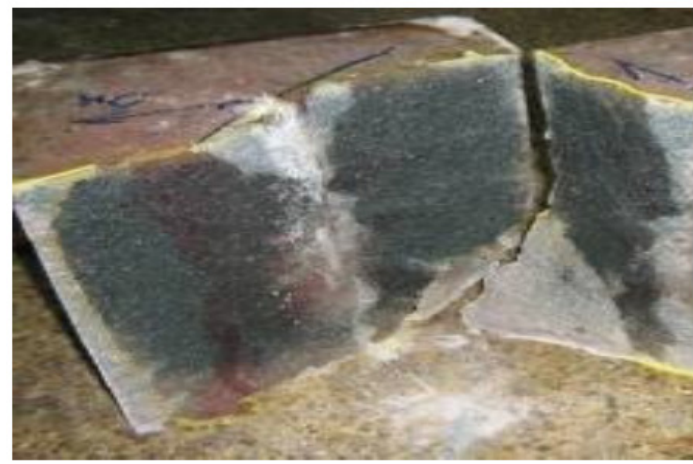

Fig. (10). The fracturing results of laboratory test of group 3 cores.

Table 1. The experimental results of rock parameters.

\begin{tabular}{|c|c|c|c|c|c|c|}
\hline Core Number & $\begin{array}{c}\text { The Group Number } \\
\text { of Test Item }\end{array}$ & $\begin{array}{c}\text { The Minimum } \\
\text { Principal Stress (MPa) }\end{array}$ & $\begin{array}{l}\text { Poisson's } \\
\text { Ratio }\end{array}$ & $\begin{array}{l}\text { Young's Modulus } \\
\text { (MPa) }\end{array}$ & $\begin{array}{c}\text { Material } \\
\text { Parameters (m) }\end{array}$ & $\begin{array}{c}\text { Material } \\
\text { Parameters }(k)\end{array}$ \\
\hline \multirow{3}{*}{$\begin{array}{c}\text { Cores of group } 1 \\
(1408.44 \sim 1440.98 \mathrm{~m})\end{array}$} & $1-1$ & 29.4 & 0.21 & 18233 & 1.45 & 16300 \\
\hline & $1-2$ & 29.4 & 0.23 & 18645 & 1.45 & 16450 \\
\hline & $1-3$ & 29.7 & 0.23 & 11983 & 1.60 & 16230 \\
\hline \multirow{3}{*}{$\begin{array}{c}\text { Cores of group } 2 \\
(1707.74 \sim 1739.59 \mathrm{~m})\end{array}$} & $2-1$ & 32.1 & 0.24 & 25907 & 1.20 & 19000 \\
\hline & $2-2$ & 32.3 & 0.20 & 19412 & 1.40 & 19100 \\
\hline & $2-3$ & 32.4 & 0.19 & 16577 & 1.50 & 19000 \\
\hline \multirow{3}{*}{$\begin{array}{c}\text { Cores of group } \\
3(849.17-976.63 \mathrm{~m})\end{array}$} & $3-1$ & 20.1 & 0.27 & 8623 & 1.70 & 15210 \\
\hline & $3-2$ & 20.1 & 025 & 8900 & 1.70 & 15200 \\
\hline & $3-3$ & 16.1 & 0.24 & 8720 & 1.70 & 15000 \\
\hline
\end{tabular}

Table 2. The comparative results between calculated fractures length and actual value.

\begin{tabular}{|c|c|c|c|c|c|c|c|}
\hline $\begin{array}{l}\text { Test Item } \\
\text { Number }\end{array}$ & $\begin{array}{c}\text { The Group } \\
\text { Number of Test } \\
\text { Item }\end{array}$ & $\begin{array}{c}\text { The Dimension } \\
\text { of Test Item } \\
\left(\mathrm{cm}^{\wedge} 3\right)\end{array}$ & $\begin{array}{c}\text { The Strain } \\
\text { Value of Rock } \\
\text { Body } \\
\text { Catastrophe } \\
\text { Bursting }\end{array}$ & $\begin{array}{c}(\mathrm{J}) \\
\text { The Energy } \\
\text { Release Value }\end{array}$ & $\begin{array}{l}\text { The Theoretical } \\
\text { Fractures } \\
\text { Propagation } \\
\text { Semi-length } \\
\text { (cm) }\end{array}$ & $\begin{array}{c}\text { The Experimental } \\
\text { Fractures } \\
\text { Propagation } \\
\text { Semi-length } \\
(\mathrm{cm})\end{array}$ & $\begin{array}{c}\text { Proportional } \\
\text { Error } \\
(\%)\end{array}$ \\
\hline \multirow{3}{*}{ Test item 1} & $1-1$ & $30 * 30 * 30$ & 0.0051 & -227.08 & 13.978 & 12.90 & 7.71 \\
\hline & $1-2$ & $30 * 30 * 30$ & 0.0048 & -201.66 & 13.642 & 12.80 & 6.17 \\
\hline & $1-3$ & $30 * 30 * 30$ & 0.0048 & -312.84 & 13.622 & 12.30 & 9.71 \\
\hline
\end{tabular}


(Table 2) contd....

\begin{tabular}{|c|c|c|c|c|c|c|c|}
\hline $\begin{array}{l}\text { Test Item } \\
\text { Number }\end{array}$ & $\begin{array}{c}\text { The Group } \\
\text { Number of Test } \\
\text { Item }\end{array}$ & $\begin{array}{c}\text { The Dimension } \\
\text { of Test Item } \\
\left(\mathrm{cm}^{\wedge} \mathbf{3}\right)\end{array}$ & $\begin{array}{l}\text { The Strain } \\
\text { Value of Rock } \\
\text { Body } \\
\text { Catastrophe } \\
\text { Bursting }\end{array}$ & $\begin{array}{c}\text { (J) } \\
\text { The Energy } \\
\text { Release Value }\end{array}$ & $\begin{array}{l}\text { The Theoretical } \\
\text { Fractures } \\
\text { Propagation } \\
\text { Semi-length } \\
\text { (cm) }\end{array}$ & $\begin{array}{l}\text { The Experimental } \\
\text { Fractures } \\
\text { Propagation } \\
\text { Semi-length } \\
\text { (cm) }\end{array}$ & $\begin{array}{c}\text { Proportional } \\
\text { Error } \\
(\%)\end{array}$ \\
\hline Test item 2 & $2-1$ & $30 * 30 * 30$ & 0.0049 & -381.88 & 13.057 & 12.40 & 4.96 \\
\hline \multirow{3}{*}{ Test item 3} & $3-1$ & $30 * 30 * 30$ & 0.0054 & -326.62 & 13.658 & 15 & / \\
\hline & $3-2$ & $30 * 30 * 30$ & 0.0054 & -340.14 & 15.841 & 15 & I \\
\hline & $3-3$ & $30 * 30 * 30$ & 0.0056 & -305.84 & 13.559 & 14.30 & -5.47 \\
\hline
\end{tabular}

(2) The cracks propagation energy release value and propagation length of different depth reservoirs were calculated, according to the rock body in a certain block of Daqing oil field. The maximum error between theoretical and the actual result is $9.71 \%$. The calculated cracks propagation parameters basing on catastrophe theory is in good agreement with the experimental ones.

\section{CONFLICT OF INTEREST}

The authors confirm that this article content has no conflict of interest.

\section{ACKNOWLEDGEMENTS}

This work is financially supported by China Postdoctoral Science Foundation Funded Project (2014M550180), Youth Science Foundation of Northeast Petroleum University (2013NQ105), The Scientific Research Fund of Heilongjiang Provincial Department of Education (12521057), The Scientific Research Fund of Heilongjiang Provincial Department of Education (12541090), PetroChina Innovation Foundation (2011D-5006-0212), The National Natural Science Foundation of China (51104032), PetroChina Innovation Foundation (2013D-5006-0209), and Academic Backbone of Heilongjiang Province University Youth Support Program (1253G011).

\section{REFERENCES}

R.S. Zhang, Q. Wang, and Z.G. Zhang, "Research of ABAQUS numerical simulation of 3D fracture propagation in hydraulic fracturing process," Oil Drilling \& Production Technology, vol. 34, pp. 69-72, 2012.

[2] L.C. Jia, M. Chen, L.T. Sun, Z.Y. Sun, W. Zhang, Q.Q. Zhu, Z. Sun, and Y. Jin, "Experimental study on propagation of hydraulic fracture in volcanic rocks using industrial CT technology," Petroleum Exploration And Development, vol. 40, pp. 377-380, 2013.

[3] Y. Yang, F.J. Biao, and H. Wang, "A numerical study on effects of helical perforation on hydraulic fracturing of horizontal fractures," Acta Petrolei Sinaca, vol. 33, pp. 1076-1079, 2013.
[4] H.Y. Zhu, J.G. Deng, S.J. Liu, W. Yan, Z.R. Chen, M. Wen, and C.Y. Peng, "A prediction model for the hydraulic fracture initiation pressure in oriented perforation," Acta Petrolei Sinaca, vol. 34, pp. 556-562, 2013

[5] Z.F. Yan, Y.W. Ju, S.H. Tang, Q.L. Hou, B.C. Zhu, and G.C. Wang, "Numerical simulation study of fracturing process in coalbed methane reservoirs in southern Qinshui basin," Chinese Journal of Geophysics, vol. 56, pp. 1735-1743, 2013.

[6] G.M. Zhang, H. Liu, J. Zhang, H.A. Heng, and X.X. Wang, "Three-dimensional finite element numerical simulation of horizontal well hydraulic fracturing," Enginerring Mechanics, vol. 28, pp. 101-106, 2011.

[7] W.C. Zhao, "Study of rock mass nonlinearity damage evolutionary on hydraulic fracturing," Ph. D. Thesis, Da qing: Daqing Petroleum Institute, 2009

[8] W.C. Zhao, C.Y. Sun, C. Wang, C Ai, and Z.D. Bu, "Study damage of rock and evolvement of porosity and permeability under hydraulic fracture in Ji Lin oilfiled," SPE Production Engineering, vol. 6, pp. 1-4, 2010.

[9] W.C. Zhao, C. Ai, Y.W. Li, and B.Y. Guo, "Study on rockmass deteriortion and changes of porosity and permeability in doubleporosity medium under hydraulic fracture based on damage theory," Chinese Journal of Rock Mechanics and Engineering, vol. 28(sup 2), pp. 3490-3496, 2009.

[10] Y.H. Chen, "Research on the hydraulic fracturing mechanics theory of tuffaceous formation in Hailaer oilfield," Ph. D. Thesis, Da qing: Daqing Petroleum Institute, 2008

[11] F.H. Ling, "Catastrophe theory and its application,"Shanghai: Shanghai Jiaotong University Press, 1987

[12] L.M. Zhang, Z.Q. Wang, X.J. Zhang, and Z.Q. Wang, "Fold catastrophe model of rock dynamic destabilization," Chinese Journal of Geotechnical Engineering, vol. 31, pp. 552-557, 2009.

[13] Y. Pan, and Z.Q. Wang, "Research approach on increment of work and energy - catastrophe theory of rock dynamic destabilization," Chinese Journal of Rock Mechanics and Engineering, vol. 23, pp. 1433-1438, 2004.

[14] Y. Pan, and Z.Q. Wang, "Fold catastrophe model of circular tunnel rock burst," Rock and Soil Mechanics, vol. 26, pp. 175-182, 2005.

[15] L.M. Zhang, and Z.Q. Wang, "Reply to the discussion on Fold catastrophe model of rock dynamic destabilization," Journal of Rock Mechanics and Geotechnical Engineering, vol. 32, pp. 160$162,2010$.

[16] S.W. Yu, and X.Q. Feng, "Damage mechanic," Tinghua University Publishing, 1997.

(C) Wanchun et al.; Licensee Bentham Open.

This is an open access article licensed under the terms of the Creative Commons Attribution Non-Commercial License (http://creativecommons.org/licenses/by-nc/3.0/) which permits unrestricted, non-commercial use, distribution and reproduction in any medium, provided the work is properly cited. 